\title{
A FORMAÇÃO EDUCATIVA E POLÍTICA DAS ONGs NO CIBERESPAÇO E NO LUGAR: O CASO DO CDDHMP-DHNet ${ }^{1}$
}

\author{
Carlos Alberto Lopes de Sousa ${ }^{2}$ \\ Faculdade de Educação da Universidade de Brasília (UnB) \\ carloslopes@unb.br
}

\begin{abstract}
RESUMO
O artigo analisa o caso da atuação da ONG CDDHMP - Centro de Defesa dos Direitos Humanos e Memória Popular (Natal - RN) que, por meio da DHNet, criada em 1 de maio de 1994, utiliza as tecnologias da informação e comunicação em causas vinculadas aos direitos humanos (formação e ação política), à difusão da cultura popular e ao acesso e o uso sistemático da internet por parte organizações e cidadãos em prol do combate à exclusão social, econômica e cultural e, nos termos de Lojkine (1995), contra o monopólio do pensamento. O trabalho foi elaborado a partir de pesquisa documental e entrevista. $\mathrm{O}$ texto apresenta a concepção de revolução informacional de Lojkine (1995) e a questão conceitual sobre ONGs e, ainda, a concepção de educação e comunicação nos termos de Freire. $\mathrm{O}$ artigo conclui que quanto maior a possibilidade de encontros e de comunicação face a face, por parte dos agentes das ONGs ou intermediários qualificados, em determinada faixa de tempo, e a ocorrência de fatos indutores para ação, maior poderá ser o sentido que se atribui para o uso da internet por parte das ONGs. A partir da ação em lugares dá-se sentido para capilarizar e globalizar virtualmente, temas, lutas, atividades e denúncias relacionadas aos direitos humanos.
\end{abstract}

Palavras-Chave: Educação; ONGs; Lugar; Ciberespaço.

\section{EDUCATIONAL AND POLITICAL TRAINING OF NGOS ON IN CYBERSPACE AND IN HE LOCAL: THE CASE OF CDDHMP-DHNet}

\begin{abstract}
The article analyses the case of the NGO CDDHMP - Centre for Human Rights and Popular Memory (Natal -RN) which, via DHNet, established on 1 May 1994, uses information and communication technologies to support human rights-related causes (political education and action), the diffusion of popular culture and the access and systematic use of the internet by organizations and citizens in favour of combating social, economic and cultural exclusion and, in Lojkine's terms (1995), to support causes against the monopoly of thought. The paper draws from archival research and interviews. It presents the concept of the information revolution by Lojkine (1995) and the conceptual discussion on NGOs as well as the concepts of education and communication according to Freire. The article concludes that the greater the possibility of face-to-face meetings and communication between NGOs' agents or qualified intermediaries in a particular period, as well as the occurrence of facts inductive to action, the greater the meaning attributed to the use of internet by NGOS. From action in a specific place, it provides meaning to virtually spread and globalize issues, struggles, activities and complaints about human rights abuses. Keywords: Education; NGOS; Place; Cyberspace.
\end{abstract}




\section{Introdução}

Uma das experiências marcantes na década 60 no campo da educação e comunicação, com ênfase no trabalho junto às camadas populares do Norte e Nordeste do Brasil, ocorreu por meio da atuação do Movimento de Educação de Base - MEB. A pauta do MEB trazia à discussão, entre tantos outros temas, as práticas, as concepções e modos de utilização do rádio, notadamente, discutindo a natureza do processo de educação, comunicação e politização de grupos específicos, bem como da sociedade em geral, para os quais eram elaborados os conteúdos dos programas radiofônicos. Os programas radiofônicos do MEB tinham projeto global de intervenção educativa e política em determinados municípios, articulado ao trabalho de animação popular nas comunidades. Portanto, o rádio não era utilizado com finalidade que se esgotava na simples emissão radiofônica. A emissão radiofônica era combinada à presença física do agente educativo em grupos e organizações comunitárias locais.

As necessidades básicas da população, as denúncias, as convocações para $01^{\circ} \mathrm{de}$ maio e romarias da terra, as notícias das comunidades, as campanhas pelo voto consciente e a participação das lideranças comunitárias e sindicais tinham espaço na agenda dos programas radiofônicos, evidenciando o compromisso e envolvimento do pessoal do MEB em ações de natureza educativa e política. As características da educação popular assumidas pelo MEB levavam em consideração o processo educativo existente; contribuía para a consciência crítica e a transformação social; abrangia as várias dimensões dos grupos populares; pressupunha um projeto histórico; assumia como vivência as pequenas transformações, tendo em vista a transformação maior; reconhecia o valor do povo, sua cultura, sabedoria; considerava o povo como agente primeiro e principal do processo educativo; atuava em espaços determinados (comunidades, organizações); devia fazer surgir uma ação em cadeia não se restringindo a grupos isolados ou desarticulados (MEB, 1987, p. 7-8).

Dantas (2002, p. 102) frisa que nos Estados Unidos, nas décadas de 1910 e 1920, muitas pessoas puseram-se a montar e a utilizar equipamentos de radiotransmissão, trocando informações sobre tudo. Esse mesmo autor, referindo-se a Bertolt Brecht, salienta que sua percepção sobre a liberdade de acesso ao espectro eletromagnético o levou a formular a "teoria do rádio". Tal teoria propunha dotar as residências com aparelhos emissores-receptores por meio dos quais os cidadãos poderiam manter relações culturais e políticas. Em tal proposição subjaz uma utopia democrática de movimentação do cidadão em uma arena pública mediada pela comunicação. Muitas pessoas que se envolveram com as Escolas Radiofônicas no MEB foram movidas por alguma utopia que as instigaram a romper a visão sócio-técnica dos aparelhos de rádio como meros elementos da emissão e recepção de voz. Na história dos movimentos de educação e cultura popular o MEB é um exemplo do uso inovador do rádio na educação de base e, inclusive, no campo da modalidade educativa a distância.

Hoje, com o advento da internet, essa utopia comunicacional é revigorada na teia conceitual do que se proclama como sociedade da informação ${ }^{3}$. O IBASE - Instituto de Análises Sociais e Econômica, ONG criada em 1981, que teve como um dos fundadores o sociólogo Herbert de Souza (o Betinho), foi organização pioneira na comunicação mediada por computador. Com dois anos de criação o IBASE conseguiu gerar um grande impacto na opinião pública com a divulgação dos dez maiores latifúndios do país. Essa informação era guardada pelo Serviço Federal de Processamento de Dados - SERPRO e o IBASE, por meio da sua rede de colaboradores, conseguiu esse "furo" de informação (FICO, 1999, p. 40). A atitude já denotava que "dados" armazenados em bancos de informações deveriam 
ser públicos. Mas não só isso! A apropriação dos dados ganhava significado na correlação de forças entre os sujeitos que entravam em disputas de "sentido" em torno da interpretação das informações adquiridas. A disseminação da informação por meio da transmissão de dados era uma "arma" que podia ser utilizada por ONGs e expressava, na sua imediata divulgação e apropriação, a luta contra o monopólio estatal das informações. O IBASE protagonizou a criação do Alternex, o primeiro provedor não acadêmico do Brasil liderado por organização da sociedade civil. Crises internas do IBASE tiveram como desfecho a análise de que esse sistema já havia cumprido sua função de democratização das informações e que havia novas condições para a prestação de serviços telemáticos no país. Com isso, o controle do Alternex passou, definitivamente, para a iniciativa privada. A iniciativa do IBASE na comunicação mediada por computador foi importante por colocar na agenda das ONGs e instituições públicas a discussão sobre a internet no Brasil e no que esse processo, ainda novo no país, poderia ser disseminado nacionalmente e internacionalmente no campo da sociedade civil. Por esse pioneirismo histórico o IBASE provocou outras organizações a experimentarem o uso da comunicação mediada por computador, a exemplo do caso da ONG analisada nesse artigo que atua numa perspectiva da educação emancipadora.

Rheingold (1996) aborda o potencial da internet para a liberdade política e sobre a forma como as comunidades virtuais poderão vir a alterar a nossa percepção do mundo enquanto indivíduos e comunidade ${ }^{4}$. Rheingold (1996) se autoclassifica como um entusiasta do potencial libertador das comunicações mediadas por computador, todavia, reconhece que é importante ficar alerta e vislumbrar as armadilhas produzidas pela combinação tecnologia e relações humanas.

Lojkine (1995) trabalha com a concepção de que o final do século XX acenou com uma mutação na nossa civilização mercantil. Trata-se de uma mutação que se caracteriza em uma revolução informacional, definida como revolução tecnológica de conjunto que é ao mesmo tempo o anúncio e a potencialidade de uma nova civilização pós-mercantil inserida em um novo padrão de relação entre as classes sociais divididas entre os que produzem e os que dirigem a sociedade, entre os que têm o monopólio do pensamento e aqueles que são excluídos deste exercício (LOJKINE, 1995, 11-12). Lojkine (1995) aborda a revolução informacional sob a ótica das tendências em tal mutação e não pelo discurso de que se vive uma fase, digamos assim, pós-industrial.

Evidente na posição de Lojkine (1995) é o fato desse não assumir o termo "sociedade da informação" como referência e sim a ideia de revolução informacional em que a tecnologia tem papel importante como potencialidade contraditória em uma sociedade capitalista demarcada pela divisão das classes sociais. Lojkine (1995) reconhece, mesmo que de forma contraditória, que os atores da revolução informacional são todos conscientes ou não, usuários das novas tecnologias da informação. Todavia, continua Lojkine (1995, p. 309-310), se se confere aos desafios dessa revolução sua significação cultural, política e ética, o movimento social que deverá realizá-la pertence ao futuro. $\mathrm{O}$ protagonismo dos sujeitos individuais e coletivos aparece como apelo à consciência destes em função das estruturas constitutivas e instituídas, por exemplo, na política e economia e que geram crises informacionais em função das estratégias, também informacionais, que colocam em oposição as perspectivas de ação em torno das regras do lucro e as regras do serviço aos usuários com finalidade pública.

Freire (2002, p.42) bem afirma que a educação libertadora ou emancipadora tem por finalidade a conscientização daquele que aprende numa relação comunicação dialógica, afirmando o homem como sujeito. Lima (2001, p.288) diz que Freire identificou a necessidade de se repensar a comunicação como cultura: 
Cultura e comunicação, no sentido amplo de ter em comum, compartilhar, estar conectado pela mesma teia simbólica construtora de sentido, de um contexto histórico desigual e contraditório. [...] Comunicação implica um diálogo entre sujeitos mediados pelo objeto do conhecimento que, por sua vez, decorre da experiência e do trabalho cotidiano. [...] O próprio conhecimento, gerado pelo diálogo comunicativo, só será verdadeiro e autêntico quando comprometido com a justiça e a transformação social. A comunicação é, por definição dialógica (grifo no original) (LIMA, 2001, p. 288).

É na ótica do paradigma educativo voltado à formação do sujeito crítico e à cidadania ativa que situo esse artigo, abordando iniciativa política e educacional por meio das tecnologias da informação e comunicação no campo do que genericamente se classifica como educação não-formal protagonizada por organização não-governamental. Assim, o artigo trata das seguintes questões: Como se caracteriza o uso educativo e político da internet em processo formativo a distância de uma organização não-governamental na combinação das iniciativas no ciberespaço e no lugar de vida dos sujeitos? O que se depreende, da análise do caso específico, aspectos gerais a considerar em relação ao uso da internet por parte das ONGs?

Nesse trabalho assumo aquela concepção de lugar apresentada em Giddens (1991, p. 26), em termos da ideia de localidade e cenário físico da atividade social. Já ciberespaço $^{5}$ é o espaço por onde circulam e se manifestam palavras, sons, imagens, relações sociais, riqueza e poder dos sujeitos sociais - individuais e/ou coletivos utilizadores da internet, para desenvolver ações, entre outras, voltadas para a ação política e educativa.

A pesquisa realizou-se por meio de consulta a fontes documentais e entrevista semiestruturada com dirigente de ONG.

\section{As ONGs: dos dilemas da autodefinição à conexão político-pedagógica no virtual}

As ONGs conectadas em redes eletrônicas e envolvidas com o discurso emancipatório, libertário, comprometidas com práticas que dão testemunho desse compromisso, utilizam-se das possibilidades de conexão planetária para fins diversos. Mas o que são as ONGs? Wolfe (1992, p.19), o termo ONG apresenta um problema óbvio que está na sua autodefinição, segundo a qual o que não estiver na esfera do governo é ONG. Haddad (1991, p.1) afirma que as ONGs vêm ganhando crescente visibilidade na sociedade brasileira e muitas vezes são tomadas com tanta diversidade que acabam sendo responsabilizadas por tantos aspectos da intervenção social que nem sempre correspondem ao que efetivamente fazem ou são capazes de fazer, pouco se conhecendo os seus limites e as potencialidades. Ainda na mesma passagem, Haddad (1991) explicita que as ONGs nasceram durante o período militar, cresceram na década de 1980 e se tornaram visíveis e polemizadas na década de 1990 e, em 2000, sua natureza e disputa de significados se manifestaram. Essas entidades podem ser de caráter assistencial ou de promoção da cidadania, variando suas temáticas, suas formas de intervenção e de gestão. Particularmente, concebo como ONG como aquele coletivo de sujeitos sociais que não mantêm, em relação ao mercado, aos governos, entidades congêneres, relação unidirecional de subordinação e não visam, egoisticamente, a acumulação de capital econômico-financeiro. Assim, desenvolvem de forma subsidiária ou protagônica, no seu campo de atuação, em lugares e/ou no ciberespaço, junto a pessoas, grupos sociais, instituições, ações que visam mudanças em questões que afetam as condições de vida e da existência humana. 
A estratificação das ONGs em função do uso das redes e a valorização da sua utilização em contatos em nível nacional e internacional são duas vertentes das possibilidades de distinção das ONGs que atuam em um mesmo campo temático de intervenção. A estratificação que ocorre no interior de uma associação de ONGs, no que se refere à utilização das redes telemáticas, provoca níveis de distinção, tendo como identificador diferencial - sem pretensão de esgotá-los -, o próprio habitus dos agentes (leitura, escrita e capacidade de conversação em outras línguas); o tempo de atuação da ONG; a qualidade e quantidade da infraestrutura tecnológica; sua imagem socialmente construída e os recursos econômicos e financeiros disponíveis. $\mathrm{Na}$ outra vertente de destaque, a valorização das interações no plano nacional e internacional pode revelar não só conexões com temas globais colocados na agenda internacional de discussão, mas a circulação de agentes por fóruns, seminários, enfim, eventos irradiadores de discursos e práticas.

\section{Formação e Ação Política na Internet: o caso do CDDHMP-DHNet}

O Centro de Defesa dos Direitos Humanos e Memória Popular - CDDHMP, ONG criada em 1986, sediada em Natal (RN), é filiado ao Movimento Nacional de Direitos Humanos - MNDH e à Associação Brasileira de Organizações Não-Governamentais ABONG, atuando nas áreas de Comunicação, Cultura e Direitos Humanos ${ }^{6}$. O CDDHMP tem um espaço virtual que é compartilhado por outras organizações. Esse espaço virtual denomina-se DHNet. Pela DHNet há iniciativas sociais e políticas pela internet ${ }^{7}$. Dentre as iniciativas planejadas e com conteúdo disponível na internet há o curso "Agente da Cidadania", bem como, ênfase ao planejamento de "Oficinas Virtuais de Acesso à Justiça".

Do processo de inserção política e social do CDDHMP foi ao ar, ao final de 1994, o BBS Direitos Humanos e Cultura (hoje denominado DHNet), mas seu lançamento oficial foi realizado em $1^{\circ}$ de maio de 1995 . A carga simbólica da criação do BBS Direitos Humanos e Cultura, em $1^{\circ}$ de maio, é marcada pelo ideário do compromisso às causas vinculadas aos direitos humanos, à cidadania, à difusão da cultura popular e ao acesso e o uso sistemático da internet por parte das organizações da sociedade civil e cidadãos em geral, em prol do combate à exclusão social, econômica e cultural. Além do mais, 1995 representou o ano de "entrada" oficial do Brasil na internet e, especificamente, o BBS significou a passagem da linguagem analógica para a digital nas experiências já desenvolvidas no âmbito do CDDHMP $^{8}$. A Rede DHNet é um provedor de informações via internet que, segundo seus organizadores, constitui-se no maior banco de dados sobre direitos humanos no Brasil. A proposta da DHNet surgiu vinculada a um lugar em que as disputas com segmentos da oligarquia e grupos de extermínio necessitavam de um espaço virtual que servisse de elo digital para cobrir as lacunas de informação no Rio Grande do Norte ${ }^{9}$.

Entre os antecedentes e fatos que estimularam a inserção do CDDHMP no uso das redes telemáticas está a iniciativa operada pelo IBASE com as transmissões para o mundo, por computador, da Conferência das Nações Unidas sobre Meio Ambiente e Desenvolvimento, ocorrida no Rio de Janeiro (ECO/1992), via AlterNex, e da Conferência Mundial sobre Direitos Humanos, realizada em Viena (1993) ${ }^{10}$.

Em termos da realidade na qual se inseriu inicialmente a proposta da DHNet, Roberto Monte admitiu ser uma coisa "meio louca" se falar em robótica, telemática, interatividade, frente a um contexto de necessidades gritantes como falta de água ou onde ainda se registrava a presença de lombrigas. Mas ele apostou no trabalho do BBS Direitos Humanos e Cultura como um projeto mais amplo de confluência dos excluídos da sociedade e de apropriação do conhecimento tecnológico. Frente a essas contradições, 
Roberto Monte afirmou em entrevista que toda prática nova tem que estar alicerçada em ideias novas:

No momento em que um grupo vinculado a movimentos de base discute uma tecnologia de ponta, a agente também vai desmistificar a questão da comunicação. Porque a comunicação, num veículo de exploração (sic), a gente tenta reverter esse lance da opressão, transformando o veículo enquanto meio num veículo de libertação. Numa linguagem bem tecnológica da libertação. A gente tem um corte muito claro: numa sociedade de excluídos e de exclusores, de pessoas que oprimem e de oprimidos, nós estamos do lado dos lascados. Estamos do lado dos excluídos. E vamos ser a ferramenta, vamos ser o fermento, como se dizia antigamente, exatamente para levantar essa discussão [...](BBS ENGAJADA, 1995, p. 5).

A visão em relação à desmistificação das novas tecnologias da informação vem acompanhada do papel do instrumento e da linguagem como portadora da emancipação. A desmistificação passaria pela apropriação do instrumento de intervenção e utilização dos novos códigos de linguagem em fluxo informacional entre os sujeitos sociais em interação. O papel da ONG seria o de animar o fluxo em rede a partir do lugar (comunidades, municípios etc.).

A DHNet volta-se para dois grandes temas: a democratização da informação e a difusão dos Direitos Humanos. No primeiro tema busca-se aglutinar e disseminar a maior quantidade de informações no que se referem às leis, convenções e instituições de promoção e proteção dos Direitos Humanos. No segundo tema foca-se em grupos sociais alvo das violações dos Direitos Humanos e discriminados face às clivagens sócioeconômicas, como pobreza, origem migratória, gênero, geração, raça e etnia, opção sexual, portadores de necessidades especiais.

Marcada por pela visão da "glocalização", como combinação do local que busca repercutir no global e vice-versa, o conteúdo da DHNet ganha uma acentuada ênfase e valorização no lugar. É a ação voltada para a sensibilização, para a animação, para a disseminação da informação no lugar que alimenta o sentido e a perspectiva de intervenção em ambiente virtual, dando-se "testemunho a distância" das ações idealizadas e desenvolvidas. O lugar, marcado por experiências desenvolvidas em direitos humanos, publicizadas pela internet, apela para a perspectiva da formação de redes temáticas.

O espírito e a práxis 'glocais' da Rede Estadual de Direitos Humanos do Rio Grande do Norte (REDH-RN) - ou seja, a dialética constante entre micro-práticas locais de promoção, proteção e garantia de todos os direitos da pessoa, concebidos como universais e indivisíveis, e princípios e sistemas globais, tendo entre os eixos norteadores a comunicação e como suporte as tecnologias digitais [...].(CANDORELLI, 2005, s.p.)

No CDDHMP, o desafio de fazer a luta pelos direitos humanos também envolveu o planejamento de atividades educacionais a distância e presencial no formato de cursos e oficinas. Dessa forma, a educação em direitos humanos visou propiciar, de uma maneira geral, que as pessoas ficassem ligadas aos acontecimentos sociais e políticos, cônscias das responsabilidades e deveres enquanto cidadãos críticos (O POTY, [199?]). Esses cursos foram planejados para ficarem conectados ao desenvolvimento da Rede Estadual de Direitos Humanos. A concepção de educação do CDDHMP volta-se para uma visão 
dinâmica, criadora, crítica, cultural e humanista, capaz de promover mudanças e facilitar a interação entre os sujeitos.

O curso "Os Sistemas Internacionais de Proteção aos Direitos Humanos", planejado para ser realizado a distância, visava a popularização dessa temática e tinha como públicoalvo organizações, estudantes, professores, assessores, militantes e público difuso com interesse no uso desses mecanismos (MONTE, [199?]). O curso foi estruturado para ser executado em seis módulos e pautava sua metodologia pela interatividade e pelos recursos multimídia oferecidos pela internet. A favor dessa iniciativa, enfatizava-se: "A nosso favor está o fato de termos um provedor próprio (http://www.dhnet.org.br) e possuirmos knowhow em novas tecnologias, baseado em experiências com o vídeo e o sistema BBS, iniciadas em 1995”(NOTAS Introdutórias, [199?]).

A proposta de curso envolvia a realização de ciberoficinas a distância e encontros presenciais em Natal, Belém e Rio de Janeiro. Ciberoficinas virtuais, planejadas e disponibilizadas para acesso pela internet e por CD-ROM, tinham por objetivo criar mecanismos interativos através da virtualidade, utilizando os recursos facilitadores da informática. Nesse sentido, a perspectiva da interatividade era dirigida para a intervenção, promoção e difusão dos conhecimentos em direitos humanos e cidadania.

As ciberoficinas tinham como objetivos específicos:

Oferecer um ambiente de aprendizagem, via rede internet, que canalize atividades educativas e de capacitação para ativistas, pesquisadores, estudantes, professores e dirigentes ou militantes de Entidades e Organizações de Direitos Humanos, com uma visão pedagógica compatível com as demandas de formação para atuação em serviço e atividades específicas;

Oferecer, num mesmo material educacional, formas alternativas de estudo, de busca de informações e de aprofundamento sobre as questões do Sistema Internacional de Proteção aos Direitos Humanos, de acordo com as características dos potenciais usuários e as demandas de conhecimento em sua formação, e em especial nas suas atividades profissionais (NOTAS introdutórias b, [199?]).

Também disponibilizado na internet e produzido com base nas experiências de formação realizadas presencialmente, inclui-se o curso Agentes da Cidadania, igualmente com destaque especial para a temática do acesso à Justiça. Na perspectiva desse curso, os participantes envolvidos, em especial as lideranças comunitárias, compreenderiam os direitos humanos como valor universal, a questão das políticas públicas, os mecanismos de acesso à Justiça, e destacariam as demandas da própria comunidade a partir de uma nova ótica, possibilitando com isso a criação de Núcleos de Bairro/Clube de Direitos Humanos (DHNet, [2004?]).

Os conteúdos do curso Agentes da Cidadania foram concebidos e ficaram disponibilizados como "livros abertos" na internet, para o acesso livre de qualquer pessoa. Todavia, sem uma definição de prazos, sistemática de orientação e acompanhamento a distância em relação aos conteúdos. Quando cito aqui o termo "livro aberto", é pelo fato de o curso ficar totalmente disponível sem a necessidade de acessá-lo por meio de nome e senha pessoal. Portanto, os conteúdos foram disponibilizados na concepção da educação aberta e a distância, no sentido da remoção de eventuais barreiras de acesso à formação em direitos humanos pela internet.

Tanto na proposição das ciberoficinas quanto dos cursos é observável a intencionalidade dessas atividades não perderem de vista alcançar determinados segmentos 
sociais e lugares estratégicos, antevendo a possibilidade dos participantes serem "empoderados" em relação à perspectiva de intervenção local (comunidades, municípios) nas questões de defesa e de promoção dos direitos humanos, as políticas públicas, os mecanismos de acesso à Justiça, destacando as demandas da própria comunidade e possibilitando com isso a criação de Núcleos de Bairro/Clube de Direitos Humanos.

Como estratégia, tanto educativa quanto política, de intervenção que repercutisse na criação ou potencialização das organizações locais em torno da temática dos direitos humanos, o CDDHMP, como elo animador da Rede Estadual de Direitos Humanos, realizou em 2004, oito Caravanas de Direitos Humanos em municípios do Rio Grande Norte. Essas Caravanas de Direitos Humanos tiveram por objetivo:

[...] interiorizar as lutas pelos direitos humanos no Rio Grande do Norte, coletar informações sobre as realidades locais, efetuar ações de valorização da cidadania, desenvolver articulações com as mais diversas organizações da sociedade civil, incentivando a participação dos Poderes Executivo, Legislativo, Judiciário e promovendo a formação de Núcleos de Cidadania no seu município" (CDDHMP, [2004?]).

A Caravana de Direitos Humanos deslocava-se de Natal para outros municípios do Rio Grande do Norte em alguns veículos que levavam os integrantes do CDDHMP e outras pessoas da Rede Estadual de Direitos Humanos: militantes de direitos humanos, artistas populares. Ao chegar ao município realizava-se, com a participação das organizações locais, uma coleta de informações em delegacias, penitenciária, acampamento de semterra, lixão, asilo de idosos, SOS criança, informações sobre a realidade local. Os dados levantados eram discutidos e sistematizados em um momento posterior da realização da Caravana quando se debatiam, entre outros temas: Reforma Agrária e Política Agrícola, Cidadania e Meio Ambiente, Exploração Sexual Infanto-Juvenil, Estatuto e Defesa dos Idosos (CARAVANAS, [2004?]). Antevia-se como desdobramentos da Caravana de Direitos Humanos a formação de Núcleos da Cidadania ou o reforço às atividades já existentes nesse segmento. Essa idéia de Núcleos da Cidadania converge com o proposto em torno das ciberoficinas: a formação de Núcleos ou Clubes de Direitos Humanos. Sem perder de vista a vinculação entre o local e o nacional. Isto é, a formação de estruturas organizadas no plano local, vinculando-se a um Sistema Nacional de Direitos Humanos (CDDHMP; SECRETARIA ESPECIAL DE DIREITOS HUMANOS DA PRESIDÊNCIA DA REPÚBLICA, [200?]).

Essa ação no lugar tem certas características daquilo que se denominou na década de 60 de "animação popular", tal qual aquela realizada pelo MEB. Um dos aspectos característicos da animação popular, que converge com a iniciativa do CDDHMP, é a ação objetiva, visível, com repercussão e conseqüências sensíveis, sendo que ação não se estreita aos problemas imediatos e se insere como ponto de reflexão e ação no contexto de luta pela transformação das estruturas, esquemas mais humanos, sem o quê o sentido dessa ação se esvaziaria ${ }^{11}$.

Ter recursos tecnológicos e colocar um conteúdo na internet não significa dizer que se tem um curso a distância. Talvez essa apreensão do que é e de como trabalhar a distância, mesmo tendo experiências com rádio, vídeo, tv, não significaram a apropriação dessa modalidade e sua aplicabilidade por parte da ONG. Mas não foi só esse o problema para a execução do curso. Ao buscar parcerias junto a embaixadas, governos, outras ONGs, ficou evidenciado que uma ONG sozinha, do porte do CDDHMP, não dá conta desse tipo de iniciativa sem uma estrutura mínima de pessoal e de recursos econômicos para bancar os investimentos. 
É um horizonte novo para as ONGs, não só do porte e posição sócio-histórica do CDDHMP, estruturar iniciativas educacionais a distância. Isso devido às exigências que se apresentam tanto na concepção quanto desenvolvimento e avaliação desse tipo de iniciativa. A ONG, familiarizada com a inserção local, com a relação face a face, ao envolver-se com a educação a distância, deve dedicar considerável parte do seu tempo para se reposicionar diante de um novo paradigma educacional, conseqüentemente, reavaliando as noções de lugar e espaço virtual. Para esse intento, a constituição de parcerias agrega valor à iniciativa. A Universidade Federal da Paraíba é apontada como parceira privilegiada pela abertura e a realização de atividades de formação em direitos humanos nos níveis de extensão universitária e curso de especialização para militantes e profissionais interessados nesse segmento de atuação (DHNet. Formação em..., set., 2011). A relação de identidade com a Universidade Federal da Paraíba está expressa no conteúdo da DHNet. Nela há uma seção específica com textos voltados para a formação em direitos humanos cuja contribuição advém de professores da Universidade Federal da Paraíba com atuação no campo dos direitos humanos. Dessa forma, não só o apoio de pessoal especializado em educação a distância, mas contando com suporte tecnológico a ONG pode viabilizar projetos nessa modalidade.

Outra vertente importante em torno do desenvolvimento de cursos a distância, como também, da ação política, está no desafio de implantar processos de interatividade no ambiente virtual da DHNet.

Na verdade eu nunca tive um suporte de interatividade que levasse a isso. [...] Na verdade a DHNET é um lance burro. Ela tem muita informação, mas não tem interatividade. Ela, a partir de agora, vai ter interatividade e eu, talvez, possa te dar uma reposta. (MONTE, Entrevista).

Reside nesse aspecto da interatividade a concepção de ambientes virtuais preparados para possíveis mediações intersubjetivas e manifestações de prováveis usuários que visitem a página da DHNet. Mas não só! É necessário também pessoal com tempo para estar em sintonia com o projeto de interatividade desenvolvido pela ONG.

\section{Considerações finais}

Para uma ONG que já tem uma trajetória de concepção, produção e utilização de diferentes midias em seu processo de trabalho, não é a internet que ordena, imperativamente, sua nova dinâmica social como disseminadora de informações e de argumentos produzidos por especialistas que se voltam para a luta democrática. A internet é apenas mais um canal que associa os outros meios para promover a participação e a democracia. Os sujeitos coletivos são, em potencial, partícipes importantes do jogo democrático para a mudança social.

A internet, como produto da ação social, é um instrumento importante de comunicação e informação na sociedade contemporânea. Ao tempo que a considero produto, tomo-a, também, como tema identificador de um momento histórico ao abrir possibilidades de se constituir uma rede de relações humanas ou de propiciar a relação entre pessoa e máquina.

Assim como o acesso ao livro - também expressão tecnológica -, a apropriação da internet é desigual pelas classes e segmentos sociais específicos. As próprias ONGs se apropriam de forma desigual da internet. $\mathrm{O}$ dinamismo da sociedade brasileira, enquanto acesso e apropriação social desigual das novas tecnologias da informação e comunicação, é diferenciado tanto em termos geográficos quanto em certos segmentos sociais. Por parte das ONGs, o desenvolvimento tecnológico e, particularmente, o fluxo informacional no 
ciberespaço, possibilitado pela internet, também tende a ser encarado de forma diferenciada nos cenários da ação dessas organizações.

O fato de uma ONG ter acesso à internet não a faz diferente de outra por si só. $\mathrm{O}$ grande risco que uma ONG corre, ao incorporar a internet como um conteúdo ou como um dos projetos político da sua intervenção ou ainda como simples ferramenta para a intervenção, é de naturalizar que as condições para a sua ação nesse eixo se reduzem à sua conexão. Vale assinalar que as dimensões conteúdo, projeto, intervenção podem ser interrelacionadas. Todavia, podem se encontrar em estágios diferenciados quanto à perspectiva do uso educativo e político. Aliás, as duas últimas dimensões, projeto e intervenção, têm maior proximidade. Há casos em que uma ONG tem a internet como projeto, mas não faz intervenção. Há casos em que na ONG a internet é um dos projetos dentro da área de comunicação e que exige condições para seu uso efetivo. Há também casos em que a internet não é considerada um projeto da entidade, mas sim um espaço de intervenção. Em todas as dimensões há condições específicas que a ONG deve ter para operar a internet.

O CDDHMP não tem como foco ser um elaborador sistemático de argumentos especializados para a discussão no campo dos direitos humanos no sentido de constituir-se como uma ONG de especialistas. Ela, a ONG, é animadora para as informações e ações em Rede, sendo a DHNet um dos seus instrumentos de publicização e intervenção em torno dos direitos humanos. Dessa forma, o CDDHMP entra em um circuito como organização que valoriza politicamente a circulação social e política da informação em redes. Portanto, a internet volta-se para a construção de uma informação independente, democrática, aberta e horizontal. A internet, como rede de relações humanas, é vista como a oportunidade para amplificar virtualmente a ação política e educativa, reunindo pessoas, coletivos, a partir do lugar que estejam.

Há ONGs, como o CDDHMP, que incorporaram a ideia da intervenção em redes, valorizando a animação em lugares. Quanto maior a possibilidade de encontros e de comunicação face a face, por parte dos agentes das ONGs ou intermediários qualificados, em determinada faixa de tempo, e a ocorrência de fatos indutores para ação, maior poderá ser o sentido que se atribui para o uso da internet por parte das ONGs. O que se denomina aqui de fatos indutores para a ação são, principalmente, aquelas atividades reativas ou não planejadas pela ONG e que provocam a possibilidade de sensibilização, iniciativas, encontros presenciais de caráter político ou educativo. As caravanas de Direitos Humanos, promovidas pelo CDDHMP são a expressão da ação direta "in loco", que repercutem no espaço virtual como "um exemplo" da combinação necessária e importante entre o presencial e o a distância. Esses são exemplos de fatos indutores realizados pelo CDDHMP.

A partir da ação em lugares dá-se sentido para capilarizar e globalizar temas, lutas, atividades, denúncias, agendas relacionados aos direitos humanos. Mas a projeção não é apenas do conteúdo manifestado por meio da internet. Assim como na internet é possível encontrar cursos a distância como "livros abertos", sem mediações intersubjetivas, o contrário também é verdadeiro. Quando me refiro às mediações intersubjetivas, quero dizer da relação educativa, presencial ou não, entre o agente de uma ONG e um participante de um processo formativo a distância pela internet. E não me refiro a qualquer processo formativo a distância. Refiro-me aos cursos que estabelecem de forma clara a dimensão política da proposta educativa em consonância com o contexto sócio-histórico. Há casos, por exemplo, de cursos públicos e gratuitos pela internet - e são ainda raros que se abrem para mediações intersubjetivas, propiciando a apropriação de conteúdos socialmente significativos e o pensar sobre a realidade na qual se insere o público-alvo do curso. Tanto no caso do curso que se apresenta como um "livro" aberto quanto àquele que 
tem toda uma estrutura de acompanhamento e orientação a distância, por parte da ONG, é preciso ter as condições básicas para a oferta da atividade formativa a distância.

Vale alertar para o fato de que a dinâmica social presencial, desenvolvida por uma ONG ou grupo de ONGs, não pode correr o risco de imaginar que a velocidade e a instantaneidade das relações por meio da internet se reproduzam em mudanças sociais também velozes. A luta, a disputa política presencial, seja com palavras ou gestos, é bem diferente daquela em que se cria a sensação do conflito virtual. Sensação essa que até é admissível ocorrer virtualmente. Todavia, é necessário que os sujeitos das ONGs evitem certos mimetismos em relação ao presencial.

Por fim, a vertente da formação a distância não deve ser tomada como mera transmissão da informação ou tecnologia instrucional e afirmo que “(...) é indispensável a compreensão de que a educação a distância não significa 'estar distanciado do outro' mas que uma via de dupla mão está em funcionamento, sobretudo em função do período de crítica, criatividade e práxis." (EMERENCIANO, LOPES DE SOUSA, FREITAS, 2001, p. 6). Já a vertente política, reportando-me ao pensamento de Rheingold (1996, p.348), os ativistas "on line" devem investigar as críticas que lhe são feitas, de que a ideia de colocar computadores nas mãos dos cidadãos como forma de se proteger das autoridades totalitárias traz à memória convicções antigas sobre o poder da tecnologia a serviço dos cidadãos. Enfatiza ainda Rheingold (1996) que a construção de fato da democracia eletrônica não pode se limitar a evitar os erros, e em vez de se cair na tentação de um anúncio de saldos ou de rejeição das novas tecnologias como instrumento de ilusão, é preciso o exame atento e o questionamento de como essas tecnologias poderão ajudar a construir comunidades coesas e mais humanas ou construir obstáculos a esse fim. Como bem afirma Maia (2002), é necessário levar em consideração que o fortalecimento da democracia não se reduz às estruturas comunicacionais eficientes e instituições propícias à participação, mas, também, devem envolver a motivação, o interesse e a disponibilidade dos cidadãos para se envolverem em debates.

\section{Referências:}

AUGUStO, Paulo. Cidadania ao alcance das mãos: tecnologia. O Poty, Natal (RN), [199?].

BATE-PAPO EM MEIO ELETRÔNICO entre Roberto Monte e Marlene de Araújo em [2001?]. Arquivo pessoal de Roberto Monte em CD-ROM.

BBS ENGAJADA: informática reforça direitos humanos. Jornal de Natal. 1 maio 1995. Caderno de Informática, p. 5.

CANDORELli, Antonio. $1^{\circ}$ de maio de 2005: 10 anos de dhnet. Tecido Social, Natal $(\mathrm{RN})$, n. 133, 27 abr. 2005. Edição em meio eletrônico recebida por e-mail.

CDDHMP. Participe das caravanas de direitos humanos. Natal (RN), [2004?]. Cartaz colorido.

CDDHMP. Arquiteturas globais: direitos humanos no Rio Grande do Norte (2005-2015). Natal (RN), jan. 2005. $1^{\text {a }}$ versão.

CARAVANAS de direitos humanos 2: Mossoró. Direção geral Roberto Monte/CDDHMP. Natal (RN) : CDDHMP, [2004?]. Vídeo em CD-ROM. 
CDDHMP; SECRETARIA ESPECIAL DE DIREITOS HUMANOS DA PRESIDÊNCIA DA REPÚBLICA. Vamos criar um conselho municipal de direitos humanos. Natal, RN. [200?]. Cartilha.

DHNET. Página eletrônica com informações e serviços variados sobre direitos humanos e cidadania. Disponível em:<http://www.dhnet.org.br/inedex.htm>. Acesso em: 1 abr. 2012.

DHNet. Formação em direitos humanos na universidade. Disponível em:< http://www.dhnet.org.br/w3/cdhpb/cursos/acao.html>. Acesso em: 1 abr. 2012.

DANTAS, Marcos. A lógica do capital-informação. 2. ed. Rio de Janeiro : Contraponto, 2002.

DHNET. Página eletrônica com informações e serviços variados sobre direitos humanos e cidadania. Disponível em:<http://www.dhnet.org.br/inedex.htm>. Acesso em: 1 abr. 2012.

DHNET. Curso agentes da cidadania: fundamentos. Disponível em:< http://www.dhnet.org.br/educar/curso/index.htm>. Acesso em: 1 abr. 2012.

CDDHMP. Participe das caravanas de direitos humanos. Natal (RN), [2004?]. Cartaz colorido.

EMERENCIANO, Maria do Socorro J.; LOPES DE SOUSA, Carlos Alberto; FREITAS, Leda Gonçalves de. Ser presença como educador, professor e tutor. Colabora, Curitiba, v. 1, n. 1, p. 4-11, ago. 2001. Disponível em:< http://www.ricesu.com.br/colabora/n1/artigos/n 1/id02.pdf.> Acesso em: 1 maio 2012.

FICO, Carlos. Ibase: Usina de ideias e cidadania. Rio de Janeiro : Garamond, 1999.

FREIRE, Paulo. Extensão ou comunicação? Rio de Janeiro, RJ : Paz e Terra, 2002.

Terra, 1986.

Educação como prática para a liberdade. 17. ed. Rio de Janeiro: Paz e

GIDDENS, Anthony. As consequências da modernidade. 2.ed. São Paulo : Editora da Universidade Estadual Paulista, 1991.

HADDAD, Sérgio. Apresentação. Cadernos ABONG: ongs, identidade e desafios atuais, São Paulo, n. 27, p.1-2, maio 2000.

LIMA, Venício A. de. Comunicação e cultura no fim do século XX: a atualidade de Paulo Freire. In. FREIRE, Ana Maria (org.). A Pedagogia da libertação em Paulo Freire. São Paulo : Editora UNESP, 2001.

LOJKINE, Jean. A revolução informacional. São Paulo : Cortez, 1995.

MAIA, Rousiley C. M. Redes cívicas e internet: do ambiente informativo denso às condições de deliberação pública. In: EINSENBERG, José; CEPIC, Marco (orgs). Internet e política. Belo Horizonte : Editora UFMG, 2002.

MEB. Cadernos MEB. MEB hoje: avaliação e prospectivas. Brasília : MEB, 1987. (Série Documento, n. 1).

MONTE, Roberto. Registro de entrevista concedida a Carlos Alberto Lopes de Sousa. Natal (RN), 2005.

MONTE, Roberto. Proposta do curso interativo sobre sistemas internacionais de proteção aos direitos humanos. In: ENCICLOPÉDIA DIGITAL DE DIREITOS HUMANOS. Natal (RN), v. 1, [199?]. CD-ROM. Áudio sobre o curso interativo. 
MONTE, Roberto. Carta à Maya Mitre. Resposta de um formulário a uma pesquisadora mineira. Disponível em:<http://www.dhnet.org.br/w3/teiavida/digital/maya_rom.htm>. Acesso em: 1 maio 2012.

NOTAS introdutórias sobre o curso sistemas internacionais de proteção aos direitos humanos. Enciclopédia Digital de Direitos Humanos, Natal (RN), v. 1, [199?]. CDROM.

NOTAS introdutórias b: o que são as ciberoficinas. Enciclopédia Digital de Direitos Humanos, Natal (RN), v. 1, [199?]. CD-ROM.

RHEINGOLD, Howard. A comunidade virtual. Lisboa, Po : Gradiva, 1996.

SOUSA, Carlos Alberto Lopes de Sousa. ONGs e internet: da ação educativa e política no lugar ao ciberespaço. São Paulo : PUC/SP, 2005. Tese de Doutorado em Ciências Sociais (Sociologia).

WOLFE, Alan. Três caminhos para o desenvolvimento: mercado, Estado e sociedade civil. In: ENCONTRO INTERNACIONAL DE ONGs E O SISTEMA DE AGÊNCIAS DAS NAÇÕES UNIDAS, 1, 1992, Rio de Janeiro. Desenvolvimento, cooperação internacional e as ONGs. Rio de Janeiro : IBASE : PNUD, 1992, p. 17-34.

\section{Notas:}

${ }^{1}$ Esse artigo foi elaborado a partir da pesquisa de doutorado em Ciências Sociais (Sociologia), sob título "ONGs e internet: da ação educativa e política no lugar ao ciberespaço". O texto foi originalmente apresentado no VI Colóquio da AFIRSE - Associação Francófono Internacional de Pesquisa Científica em Educação, realizado na UFPI (2011), com o nome "Educação e Glocalização: a Formação Educativa e Política de ONGs no Ciberespaço e no Lugar", sendo revisto e ampliado para fins dessa publicação.

${ }^{2}$ Doutor em Ciências Sociais (Sociologia) pela PUC - São Paulo. É professor do Departamento Teoria e Fundamentos (TEF) da Faculdade de Educação da Universidade de Brasília (UnB) e integra o Programa de Pós-Graduação em Educação (PPGE), orientando pesquisa na área de Educação, com ênfase em Educação, Comunicação e Tecnologias.

3 Darnton (2000) afirma que se faz tanta projeção sobre o futuro que se esquece da importância da informação no passado, principalmente, em relação à ideia de que cada era foi, à sua própria maneira, uma era da informação.

${ }^{4}$ Para Rheingold (1996, p. 18), as comunidades virtuais "são os agregados sociais surgidos na Rede, quando os intervenientes de um debate o levam por diante em número e sentimento suficientes para formarem teias de relações pessoais no ciberespaço". Vale acrescentar que o livro apresenta vivências e observações do autor sobre sua inserção em redes eletrônicas (comunidades virtuais), em especial, a Whole Earth 'Lectronic Link - WELL. A Well é definida por Rheingold (1996, p. 13) como um sistema de teleconferência por computador que permitia aos usuários, espalhados pelo planeta, a participação em conversas públicas e a troca de mensagens privadas via correio eletrônico. Conforme Rheingold (1996, p. 22), a WELL tinha como componente telúrica as Bulletin Board Systems - BBS (Sistemas de Painel de Mensagens Eletrônicas), organizada em BBS religiosas, BBS políticas, BBS fora da lei, BBS para o cumprimento da lei, BBS para deficientes, BBS das organizações sem-fins lucrativos, e estas eram constituídas por um grupo de indivíduos que ligavam para um número da sua rede telefônica local, restrita à uma área geográfica local. As BBS tiveram, nos Estados Unidos, sua origem nos anos 70 e expansão nos anos 80. As BBS são tomadas por Rheigold (1996) como referências de comunidades virtuais no ciberespaço.

${ }^{5}$ O termo ciberespaço foi utilizado pela primeira vez pelo escritor de ficção científica Gibson (1984), em romance intitulado "Neuromanter". Rheingold (1996, p.18) resgata essa concepção original designando-a como "[...] o espaço conceptual onde se manifestam palavras, relações humanas, dados, riqueza e poder dos utilizadores da tecnologia da CMC”. Optei por fazer uma ampliação desse conceito, introduzindo nele a noção de sujeito social. 
${ }^{6}$ DHNET. Página eletrônica com informações e serviços variados sobre direitos humanos e cidadania. Disponível em:<http://www.dhnet.org.br/inedex.htm>. Acesso em: 1 maio 2012.

${ }^{7}$ O CDDHMP/DHNet foi escolhido para a pesquisa por representar exemplo significativo, com repercussão local e internacional da atuação sistemática e regular, no uso educativo e político das novas tecnologias da informação e comunicação, no campo da Educação em Direitos Humanos. O autor desse artigo também pesquisou outras ONGs que fazem uso das TICs com propósitos educativos e políticos, mas para esse artigo selecionou essa organização por sua relevância e atuação no campo dos direitos humanos.

${ }^{8}$ Informação obtida por meio de entrevista com Roberto Monte, coordenador da DHNet.

${ }^{9}$ Informação obtida em DHNET, Prêmio USP..., Acesso em: 1 maio 2012.

${ }^{10}$ Esses antecedentes foram identificados a partir de registro de bate-papo em meio eletrônico e da resposta de Roberto Monte a carta de uma pesquisadora mineira (cf. bibliografia).

${ }^{11}$ Esse traço característico da "animação popular" está presente no estudo de Wanderley (1984), sobre a experiência do Movimento de Educação de Base - MEB, em livro intitulado "Educar para Transformar".

Recebido em maio/2012

Aprovado em julho/2012 